\title{
AVALIAÇÃO DA EDUCAÇÃO PERMANENTE NO PROCESSO DE TRABALHO EM SAÚDE
}

\author{
EVALUATION OF CONTINUING EDUCATION IN THE HEALTH WORK PROCESS
}

EVALUACIÓN DE LA EDUCACIÓN PERMANENTE EN EL PROCESO DE TRABAJO EN SALUD

\author{
Luiz Anildo Anacleto da Silva ${ }^{1}$ \\ Sandra Marcia Soares Schmidt ${ }^{2}$ \\ Helena Carolina Noal ${ }^{3}$ \\ Eduarda Signor ${ }^{4}$ \\ Iris Elizabete Messa Gomes ${ }^{5}$
}

Resumo O objetivo do estudo foi conhecer as mudanças ocorridas no processo de trabalho decorrentes da educação permanente em saúde. Tratou-se de uma pesquisa qualitativa, descritiva e exploratória. Os entrevistados foram enfermeiros atuantes em serviços de saúde correspondentes a cinco unidades básicas de saúde e cinco hospitais de dez cidades do Rio Grande do Sul, Brasil, entre 2011 e 2012. Os resultados indicaram que o conhecimento dos sujeitos da pesquisa em relação à educação permanente era limitado e, de maneira geral, desconheciam-se as formas de avaliação das ações educativas. Conclui-se que a educação no trabalho, no segmento pesquisado, era desenvolvida de forma compartimentada, pontual e assistemática, e que a avaliação das ações educativas não contribuía para o aperfeiçoamento do processo educativo.

Palavras-chave enfermagem; educação permanente em saúde; avaliação; processo de trabalho.
Abstract The study aimed to get to know the changes taking place in the work process resulting from permanent health education. It was a qualitative, descriptive, and exploratory research project. The interviewees were nurses working in health services at five basic health units and five hospitals in ten cities of Rio Grande do Sul, Brazil, between 2011 and 2012. The results indicated that the research subjects' knowledge on continuing education was limited and, in general, they were unaware of how educational activities are evaluated. It is concluded that education at work, in the researched segment, was carried out in a compartmentalized, timely, and unsystematic manner, and that the evaluation of educational activities did not contribute to improving the educational process.

Keywords nursing; continuing education in health; evaluation; work process. 


\section{Introdução}

A qualificação da atenção à saúde está vinculada a diversos fatores, os quais incluem estruturação e organização dos serviços; definição de processo de trabalho; aderência a novas tecnologias; definição quantitativa e qualitativa de pessoal; disponibilidade de materiais/equipamentos e medicações; e, sobretudo, comprometimento com o desenvolvimento contínuo e permanente de ações educativas suficientemente abrangentes que permitam o desenvolvimento integral dos trabalhadores em saúde.

Considera-se a educação em saúde como uma das estratégias mais efetivas de qualificação dos trabalhadores e, consequentemente, da gestão e, de forma especial, da atenção à saúde das pessoas. Com a introdução da Política Nacional de Educação Permanente em Saúde (PNEPS), propuseram-se mudanças significativas na formação e no contínuo e permanente desenvolvimento de pessoal, as quais podem representar um marco diferencial no processo de trabalho em saúde. Nessa perspectiva, a educação permanente em saúde (EPS) assume o protagonismo da gestão da educação, ao propor mudanças nas ações educativas, nos processos de trabalho, nas organizações de saúde e, principalmente, no desenvolvimento de estratégias que possam redundar na qualificação da atenção em saúde (Brasil, 2007).

A EPS como proposta educativa tem como premissa a consolidação do Sistema Único de Saúde (SUS) nos mais diferentes cenários da atenção em saúde, de forma a articular as necessidades dos serviços e dos trabalhadores, a capacidade resolutiva e a gestão dos serviços de saúde (Brasil, 2009). Não obstante seus preceitos significarem um importante avanço na relação entre aprender e ensinar, de maneira geral as avaliações da EPS são ainda incipientes, assistemáticas, desfocadas ou inexistentes. As dificuldades em estabelecer estratégias avaliativas podem estar atreladas às formas de organização das propostas de EPS como um todo e decorre, especialmente, de fatores como ausência de planejamento, em especial de um plano pedagógico institucional de educação em saúde; fatores culturais; ações educativas focalizadas no tecnicismo reducionista; diminuto contingente de trabalhadores, com sobrecarga de trabalho; questões econômicas e financeiras; e ainda processos de trabalho compartimentados entre concepção e execução (Smeke; Oliveira, 2009).

As propostas efetivas para a avaliação da educação no trabalho ainda engatinham e precisam transcender a lógica 'quantitativa' e 'escolar', em virtude da necessidade de se avaliarem o impacto da EPS no processo de trabalho e as transformações advindas da educação que se integralizem nas formas de gestão, atenção (Silva, 2010).

A avaliação do processo educativo tem como função a busca de aperfeiçoamento das ações, assim como a reorientação e a recondução dos processos. Esta, é de importância fundamental na análise dos resultados obtidos, 
situando educadores e educandos sobre as fragilidades e potencialidades das propostas educativas. As informações advindas das avaliações, primordialmente, podem subsidiar novas proposições educativas.

A pesquisa se justificou na necessidade sentida de se conhecer com mais especificidade as formas de avaliação das ações e estratégias de educação no trabalho, assim como contribuir para a construção de propostas educativas e, consequentemente, o aperfeiçoamento da atenção e da gestão. Portanto, partiu-se da pressuposição de que as mudanças geradas no processo de trabalho, obtidas por meio de ações educativas, seriam uma das formas mais efetivas de avaliação da educação permanente.

Neste estudo, a questão central foi: que formas de avaliação vêm sendo utilizadas nas ações concernentes à educação permanente em saúde e que mudanças podem gerar no processo de trabalho da enfermagem nos serviços de saúde no estado do Rio Grande do Sul? O objetivo foi conhecer as mudanças ocorridas no processo de trabalho decorrentes da EPS.

\section{Método}

Este texto é decorrente de uma pesquisa institucional, de abordagem múltipla nos serviços de atenção básica e hospitalares. Trata-se de um estudo qualitativo, descritivo e exploratório (Gil, 2010). Os participantes foram enfermeiros atuantes em áreas correspondentes a cinco unidades básicas de saúde e cinco hospitais.

\section{Contextualização do espaço da pesquisa}

A coleta dos dados, decorrente de projeto de pesquisa institucional, ocorreu entre os meses de junho de 2011 e dezembro de 2012. Utilizou-se como instrumento de pesquisa um roteiro com perguntas semiestruturadas. As entrevistas foram gravadas digitalmente, transcritas e validadas pelos participantes do estudo. A apreciação dos dados foi realizada por meio da análise de conteúdo (Bardin, 2011).

Para a definição da população a ser estudada, adotou-se uma amostra do tipo proposital, intencional ou deliberada (Turato, 2003). O número de entrevistados foi definido como saturado em cada instituição quando se considerou atendido o objetivo da pesquisa. Nos hospitais, entrevistaram-se enfermeiros dos turnos vespertino, matutino e noturno.

Os participantes do estudo eram enfermeiros (as) atuantes nas instituições hospitalares e nos serviços de atenção básica. Adotou-se como critério de inclusão todo enfermeiros com tempo mínimo de atuação de seis meses na 
função. Excluíram-se os que atuam ou atuaram na gestão de programas educativos (coordenação de EPS, membros das Comissões de Integração Ensino Serviço, coordenação de programas educativos institucionais). Após a explicitação dos objetivos do projeto e de pleno conhecimento do termo de consentimento livre e esclarecido (TCLE), concordou em assiná-lo e participar da pesquisa.

O primeiro hospital pesquisado é público, de grande porte, que atende média e alta complexidade, possui residência médica e multidisciplinar, assim como serviço de educação no trabalho. O tempo médio de atuação dos profissionais nessa instituição é de 11 anos. Está localizado em uma cidade de aproximadamente 200 mil habitantes. O segundo hospital pesquisado é público, de grande porte, que também atende média e alta complexidade, possui residência médica e multidisciplinar, tem serviço de educação no trabalho estruturado. Neste, o tempo médio de permanência no trabalho é de seis anos. Está localizado em uma cidade de aproximadamente 1,5 milhões de habitantes.

O terceiro hospital pesquisado é privado, do tipo filantrópico, de grande porte, que atende média e alta complexidade, possui residência médica e serviço de educação no trabalho. O tempo médio de permanência no trabalho é de quatro anos. Está localizado em uma cidade de aproximadamente 90.000 habitantes. O quarto hospital pesquisado é privado, do tipo filantrópico, de grande porte, que igualmente atende média e alta complexidade, possui residência médica e multidisciplinar e um núcleo de educação no trabalho. O tempo médio de permanência no trabalho é de oito anos, aproximadamente. Está localizado em uma cidade de aproximadamente 200.000 habitantes.

O quinto hospital pesquisado é privado, de médio porte, que atende média complexidade, não possui residências, mas tem serviço de educação. O tempo médio de permanência no trabalho é de dois anos. Está localizado em uma cidade de aproximadamente 90.000 habitantes. Justifica-se a opção por essas instituições em razão da procura de similitudes e/ou diferenças nas configurações dos programas educativos.

Os entrevistados oriundos da atenção básica foram de cinco distintas localidades, com 200.000, 187.000, 90.000, 34.000 e 10.000 habitantes (números aproximados). Na atenção básica, não se evidenciou nenhum tipo de setor ou programa efetivo voltado para a educação dos trabalhadores. De maneira geral, as atividades educativas eram esparsas, nem sempre vinculadas às necessidades dos entrevistados, e educativamente dependentes da participação de terceiros. Nas secretarias de saúde, o tempo médio de atuação profissional era de 13,$2 ; 7,8 ; 3,9 ; 2,9$ anos, nos serviços 1 , 2, 4, 3, respectivamente. No serviço 5 , a média de atuação dos entrevistados era de 8 meses. A opção por essas cidades e instituições teve duplo motivo: retratar como ocorre a EPS nos dife- 
rentes cenários, ou seja, cidades de pequeno, médio e grande porte; e como ela funciona em uma diversidade de regiões e em distintas instituições.

O projeto de pesquisa foi aprovado pelo Comitê de Ética em Pesquisa da Universidade Federal de Santa Maria, mediante o parecer consubstanciado n. 23081.005729, de 23 de maio de 2011.

\section{Resultados}

Em um período de 18 meses, foram realizadas 120 entrevistas gravadas. Os entrevistados tinham tempo médio de formação de 12 anos e seis meses, enquanto o tempo de atuação nas diferentes instituições era de 11 anos e três meses. Em geral, o tempo de permanência dos enfermeiros no trabalho era maior na atenção básica em relação aos hospitais. Já nos hospitais, os tempos maiores de permanência no trabalho estavam nas instituições públicas, seguidas das filantrópicas, sendo muito menor no hospital privado - o que denotou um turnover elevado. Após os recortes necessários, os dados coletados permitiram a construção de duas categorias: 'avaliação formal do processo educativo' e 'avaliação e mudanças evidenciadas no processo de trabalho'. Em razão da vastidão de dados decorrentes da pesquisa, selecionaram-se alguns extratos para ilustrar as categorias.

Embora não houvesse a intenção de se quantificarem os dados, precisa-se ratificar que aproximadamente $89 \%$ dos entrevistados desconheciam qualquer forma de avaliação das ações educativas no trabalho. Os entrevistados eram identificados por uma letra (E), seguidos de um número de ordem; quando eram oriundos de uma instituição hospitalar, esta foi referida com a letra H. Os entrevistados procedentes da atenção básica foram identificados pela sigla AB. Portanto, ElHl refere-se ao entrevistado 1 do Hospital 1, enquanto ElAB3 refere-se ao entrevistado número 1 da atenção básica 3.

\section{Avaliação formal do processo educativo}

No contexto em que foi desenvolvida a pesquisa, evidenciou-se a existência de programas educativos na maioria das instituições hospitalares. Contudo, mesmo presentes, eram ainda modestos, compartimentados, não seriados, pouco sistematizados, assim como não tinham embasamento teórico-educativo, pois eram empiricamente reproduzidos. A PNEPS e os preceitos teóricos que a sustentam eram pouco conhecidos e utilizados. Nos hospitais, as propostas educativas eram mais 'fechadas e verticalizadas', com pouca participação e interação com educadores 'externos'. Normalmente, as ações educativas eram direcionadas ao aperfeiçoamento técnico. Na atenção básica, as 
propostas educativas mostravam-se ainda menos sistematizadas. No entanto, as propostas eram socialmente construídas, havia mais interatividade entre educadores e educandos. Nela, apreciava-se e apoiava-se a participação de 'educadores externos', principalmente docentes e discentes das universidades.

De forma geral, nos hospitais as ações educativas eram compartimentadas, pontuais e focais, destinadas quase que exclusivamente a resolver problemas técnicos específicos. Nas secretarias de saúde, as propostas educativas não eram muito diferentes. Outro fato que chamou a atenção foram as incipientes ações educativas interdisciplinares.

(...) uma avaliação, avaliação mesmo, não. A gente faz uma observação, o enfermeiro fica observando. Mas não uma observação com nota ou alguma coisa. Nas reciclagens que a gente faz, não tão frequentes, mas a gente faz de vez em quando, algumas vezes estabelecemos um instrumento para fazer a avaliação (E2AB1).

(...) modo de avaliar, não. Na verdade, a gente não tem um processo de avaliação. A gente vê, percebe melhor no dia a dia, mas não que a gente tenha uma rotina estabelecida pra avaliar. Às vezes se utiliza um questionário, que dá um retorno. Nós fizemos grupo; quando um vai pra educação permanente, ele retorna e passa pros outros colegas, como que foi feito, se foi bom (E4AB2).

(...) como eu disse, até no momento não tem. Não tem nada implantado, mas está em projeto isso. Mas acho que até metade do ano, final do ano, vai estar implantado esse projeto aí. Agora a gente faz um comparativo, pois enquanto a gente não faz um comparativo parece que a gente não produziu, que a gente não evolui (E6AB3).

A gente avalia na verdade de forma bem superficial quando se tem que repetir o mesmo treinamento, quando a gente vê que fala de novo sobre aquele mesmo treinamento, porque tem gente que ainda não melhorou, tem gente que ainda tem necessidade. Mas assim, alguma coisa mais específica pronta, padronizada. Às vezes utiliza-se questionário de perguntas fechadas para você marcar se foi bom, se foi ruim, o horário, o método (E5H5).

As asserções referidas realçaram o emprego de formas assistemáticas de avaliação dos processos educativos. Embora as mudanças não sejam sistematizadas, os sujeitos do estudo as valorizavam quando ocorridas no espaço de trabalho, o que ficou evidente quando salientaram que "enfermeiro fica observando", "percebe melhor no dia a dia", "a gente faz um comparativo". Melhor explicitando, o acompanhamento in loco de mudanças no processo de trabalho constitui-se em importante forma de avaliar o processo de trabalho. Entretanto, quando um dos entrevistados afirmou: "utiliza-se ques- 
tionário de perguntas fechadas", estava recorrendo a um modelo escolar de avaliação que se distancia dos propósitos da EPS.

O uso de formas estruturadas de avaliação permitiu que também se pudessem mensurar as ações educativas, para as quais se preconizava que a avaliação fosse feita.

(...) a avaliação é feita só, até onde eu tenho conhecimento, pela média de permanência na frequência, quem participa. Recentemente, foi feito um treinamento de parada; como será o atendimento das próximas paradas? Não existe esse feedback (E1H2).

Não temos um sistema de avaliação, acho que seria interessante uma prova após a capacitação, uma provinha para saber o que sabia antes da palestrinha e o que sabe depois. Acho que é importante saber o que foi entendido, o que foi captado da fala da capacitação (E2Hl).

A avaliação e o monitoramento dos processos educativos são essenciais na análise dos problemas e situações complexas do processo de trabalho. A contínua avaliação dos processos educativos é indispensável para continuamente evidenciar as necessidades de reorientar e propor mudanças. A frequência é importante no processo avaliativo, mas não um aspecto suficientemente fidedigno, pois ela precisa estar atrelada à participação do educando como agente ativo do processo de aprendizagem. Nas ações educativas concernentes à EPS, educadores e educandos são continuamente aprendizes, estando a ação educativa mediada pelas experiências, conhecimentos e exemplos.

Na educação no trabalho, é importante que a avaliação se oriente pelos mesmos princípios que conduzem suas práticas, ou seja, definição de necessidades e os respectivos temas educativos, estratégias, locais, horários, entre outros, intersectados com os objetivos preestabelecidos. A avaliação e o monitoramento se constituem em fonte de informação para a tomada de decisão, seja para manter o processo, seja para buscar sua reorientação e aperfeiçoamento (Bastable, 2010). A simples descrição quantitativa de dias, número de horas trabalhadas e número de sujeitos envolvidos no processo educativo não configura ou assegura um sistema de avaliação da educação permanente.

\section{Avaliação e mudanças evidenciadas no processo de trabalho}

Determinado segmento dos entrevistados teve um entendimento diferenciado sobre a avaliação dos resultados dos processos educativos. Uma das estratégias de avaliação pode ser evidenciada pelas mudanças sentidas e evidenciadas no processo de trabalho, em especial, da qualificação da atenção em 
saúde. Nesse caso, a avaliação das ações educativas pôde ser evidenciada nos resultados obtidos nos respectivos espaços de trabalho.

(...) aqui, quando eu vejo os indicadores de saúde, que refletem as práticas dos profissionais, a gente vê o quanto é necessário se implementar e priorizar a política de educação permanente, que daí reflete muito na questão da prática, não da gestão como um todo, mas da prática profissional (E3AB1).

Não tem como avaliar porque ela não está acontecendo no momento. No nosso trabalho, a gente costuma avaliar pelos resultados que a gente obtém, mas nem sempre a gente obtém os resultados que a gente tava esperando (E5AB1).

O que interessa para nós nas unidades é ver mesmo, do ver assim, no dia a dia, o que ele faz, se mudou alguma coisa, no cotidiano, sabe, não tem nenhum modelo pra tu sentar e avaliar com o funcionário que participou. Agora, avaliação mesmo não me lembra de ter feito (E2H5).

(...) na verdade, não, nem uma forma específica assim, mas o que a gente observa mesmo assim, uns que melhoram, outros que não. Mas não existe assim um modelo específico pra fazer essa avaliação. Acho que o balizador disso é a mudança comportamental à beira do leito (E9H4).

Para os respondentes, a avaliação da educação permanente podia ser observada pela maneira como o trabalho vinha sendo realizado, conforme afirmaram: "indicadores de saúde, que é o que refletem práticas dos profissionais"; "no nosso trabalho, a gente costuma avaliar pelos resultados"; "ver assim, no dia a dia, o que ele faz, se mudou alguma coisa"; "acho que o balizador disso é a mudança comportamental à beira do leito". Embora houvesse algumas asserções mais pontuais nesses recortes, os entrevistados estavam valorizando as mudanças no processo de trabalho como uma forma de monitorar os resultados das ações educativas. As mudanças geradas podiam estar ligadas a maneiras de intervir educativamente e que poderiam ser continuamente observadas no processo de trabalho. Isso significa estar presente nas atividades diárias para integralmente interatuar com os trabalhadores, e essa interação pode se constituir em uma boa estratégia de avaliação, na qual educadores e educandos dialogam e trocam experiências e conjuntamente aprendem. Essa concepção de avaliação se confirmou nas falas:

Não tem avaliação. O único processo que tem é contagem de horas de formação. É quantitativo, e somente a gestão do trabalho. Eles jogam paro sistema esse treinamento que apareceu, e conta lá na tua avaliação como horas de formação. 
É mais visível, você vê que houve a mudança, digamos, do processo, alguma técnica, alguma coisa assim ou até mesmo da mentalidade (E1H5).

Como se faz eu não sei, mas eu penso que a avaliação tem que passar por todas as fases do processo desde a implementação da supervisão (E2H2).

(...) então é válido isso, mas a gente até o momento em função daquela capacitação que teve, que todas as enfermeiras e todos os técnicos optaram que era melhor não fazer, a gente não fez, não tem nada formalizado. Então nas unidades é feito mais essa avaliação no dia a dia, mais assim no dia a dia que a gente vai vendo, se está tendo resultado ou não, do que foi exposto (E12H2).

A avaliação das ações educativas no trabalho, primordialmente, não tem função tão somente de estabelecer parâmetros quantitativos, característicos do 'modelo escolar', mas também de servir de informações no intento de realimentar o planejamento de novas propostas educativas e, consequentemente, o aprimoramento de pessoal e a qualificação da atenção e da gestão. Contudo, quando os sujeitos afirmaram que é "mais visível, você vê que houve a mudança, digamos, do processo"; e também que a avaliação é feita "no dia a dia, mais assim no dia a dia", referiam-se a mudanças geradas no processo de trabalho.

\section{O contexto vivenciado}

As ações decorrentes dos programas educativos carecem de estar associadas a um contínuo aperfeiçoamento. A educação precisa estar configurada com as necessidades e particularidades de cada segmento de trabalho, de forma a obter as transformações nos modos de gestão e atenção. A reconfiguração do processo de trabalho está representada por ações contínuas, em que a religação da tríade gestão, educação, atenção constitui-se em uma forma de fomento e fortalecimento de todos os segmentos envolvidos. Nesse atrelamento, o intento está em redimensionar a inserção da educação no processo de trabalho e, consequentemente, qualificar a atenção aos usuários.

Entende-se que a organização das propostas educativas necessariamente precisa estar vinculada às necessidades das pessoas, sejam trabalhadores, sejam usuários. Para não destoar do contexto no que se refere à avaliação das ações educativas, é preciso transcender o modelo escolar de avaliação e utilizar-se dessas informações para continuamente interagir, rever, reorganizar, impulsionar e sedimentar o processo de trabalho.

Evidencia o estudo que propostas educativas vêm sendo concebidas e desenvolvidas de forma simplista. Nestas, normalmente não se utilizam de 
embasamento teórico de sustentação, aí incluídas as formas de avaliação, e nesse modo de fazer geralmente não se tem conhecimento dos resultados, os quais são requisitos básicos para orientar ações futuras no planejamento e na execução de intervenções educativas. Os preceitos teóricos que dão embasamento às EPS não utilizados, e os participantes do estudo têm poucas e vagas noções dessa proposta. A avaliação é uma importante estratégia para se situar, redefinir o processo educativo. As informações advindas das avaliações dos processos educativos fornecem importantes subsídios à manutenção, desenvolvimento e, se necessário, reconfiguração dos programas educativos (Bastable, 2010).

A atenção, na perspectiva da integralidade do cuidado, está intrínseca e extrinsecamente vinculada às formas de ações educativas para os trabalhadores. Essa relação constitui-se no núcleo definidor do processo educativo em saúde, sendo a análise e a avaliação posterior indispensáveis para a identificação dos resultados e o impacto produzido na qualificação da atenção em saúde (Montanha; Peduzzi, 2010).

As informações advindas das avaliações permitiram tomar conhecimento das especificidades do processo de trabalho nas respectivas instituições e de como elas poderiam servir de fomento às propostas de educação no trabalho. No estudo, os participantes reconheceram a importância dos programas educativos, e alguns deles, embora não tendo se referido diretamente ao processo de trabalho, intuitivamente valorizaram as 'mudanças' ocorridas. Entretanto, não se evidenciaram estratégias preconcebidas de avaliação das propostas educativas. Inclui-se nesta situação a falta de um plano político pedagógico de educação no trabalho - sua ausência embaraça o planejamento, o levantamento de necessidades, a implementação e também a avaliação.

A avaliação periódica dos processos educativos tem por finalidade acompanhar as fases do planejamento e a eficácia no desenvolvimento dos conteúdos programáticos e das mudanças decorrentes destes - ou seja, avaliar se as ações educativas estão atingindo os objetivos propostos e, principalmente, a qualificação da atenção aos usuários. Esta se constitui em um processo dinâmico que pode, contínua e permanentemente, redirecionar a ação para a transformação (Silva; Seiffert, 2009).

Com referência à primeira categoria, a qual enfoca a 'avaliação formal do processo educativo', os entrevistados propuseram ações com o uso de instrumentos apropriados para esse tipo de avaliação, a estratégia de replicação dos conteúdos e a descrição dos educandos em relação ao que aprenderam e o quanto isso significou para a geração de mudanças no processo de trabalho. Eles consideraram que o emprego de provas escritas sobre os conteúdos como uma forma de avaliação do processo educativo (Lima et al., 2009).

Bastable (2010) propõe que a avaliação possa ocorrer em cinco espaços/momentos distintos, nos quais se incluem: o propósito, a abrangência e 
os recursos que compõem o foco avaliativo. Especificamente, os cinco ciclos englobam 'processos', 'conteúdos', 'resultados', 'impactos' e 'programas'. A avaliação de 'processo' consiste em se fazerem as adaptações nas atividades educativas em relação à pessoal, material, instalações ou objetivos da aprendizagem. Esta é parte integrante do próprio processo educativo, e se constitui em um importante componente de acompanhamento das ações educativas.

O objetivo da avaliação de 'conteúdo' está em evidenciar como os educandos adquirem o conhecimento. O seu foco está em determinar como o processo de ensino-aprendizagem interfere nos resultados imediatos, evidenciando se os objetivos foram alcançados. Nesse tipo de avaliação, pode ser usado o sistema de pré e pós-teste para mensurar o resultado da ação educativa. Na perspectiva da prática baseada em evidência, a avaliação de conteúdo está focalizada em evidências internas para determinar se os objetivos educativos foram alcançados (Bastable, 2010).

Na avaliação de 'resultado', o objetivo está em determinar os efeitos das ações educativas. Avaliam-se as estratégias educativas, os resultados obtidos pelos educandos, os objetivos alcançados. As mudanças referem-se à introdução de novos processos, novas técnicas, comportamentos, atitudes, sendo comparativamente avaliadas com os dados advindos do 'diagnóstico de necessidades'. Nesta procura-se evidenciar se os resultados foram alcançados. Algumas indagações podem orientar esse tipo de avaliação: as estratégias educativas foram adequadas? Os educandos tiveram aproveitamento? Os objetivos comportamentais e técnicos foram alcançados? (Bastable, 2010).

A finalidade da 'avaliação de impacto' está em evidenciar os efeitos da educação sobre os sujeitos, instituições ou comunidades. A abrangência da avaliação de impacto é mais ampla e complexa do que as avaliações anteriormente descritas; os recursos necessários para efetivá-la contêm instrumentos confiáveis e válidos. Incluem-se pessoas capacitadas em estatística, equipamentos e materiais necessários para coleta e análise dos dados. Na avaliação de resultados, procura-se evidenciar se as ações educativas surtiram os efeitos esperados, enquanto na avaliação de impacto busca-se determinar se as metas educativas a médio e longo prazos foram alcançadas (Bastable, 2010).

Na avaliação de 'programa', o propósito está em determinar os resultados obtidos por um departamento ou do programa como um todo. A abrangência da avaliação de programa é ampla, focada em metas gerais. Na avaliação de programa, incluem-se todos os aspectos relativos à atividade educativa: processos, conteúdos, resultados e impactos, associados com as informações dos sujeitos envolvidos no processo, como educadores, educandos, representantes institucionais e comunitários, entre outros. A avaliação de programa pode ser efetuada por pessoas da própria instituição ou consultores externos (Bastable, 2010). 
A interseção entre diagnóstico de necessidades, estratégias, implementação das ações educativas e avaliação permite a interlocução entre as necessidades sentidas e evidenciadas, o desenvolvimento das ações e os resultados educativos obtidos. A avaliação dos programas educativos como um todo transcende o modelo escolar de mensurar numericamente os resultados das atividades educativas. A avaliação busca compreender os resultados educativos como forma de manter, aperfeiçoar e redimensionar os projetos de educação no trabalho.

Os resultados esperados com base nas ações educativas dos trabalhadores estão relacionados ao desenvolvimento integral dos sujeitos e à qualificação da atenção e dos serviços. Em curto prazo, busca-se a melhoria no desempenho técnico e a minimização de eventos adversos. Na avaliação das ações educativas, precisa-se transcender a lógica acadêmica e focalizar a avaliação do impacto gerado no processo de trabalho.

Na segunda categoria, 'avaliação e mudanças no processo de trabalho', os entrevistados destacaram as transformações que podem ser evidenciadas no processo de trabalho como forma de avaliar as ações educativas. Em especial, observarem-se alterações proativas na gestão e na atenção e, principalmente, na qualidade dos serviços ofertados.

$\mathrm{Na}$ avaliação das ações educativas, podem-se utilizar informações como notas descritivas sobre o cotidiano de trabalho; os aspectos positivos e as dificuldades observadas na implementação das propostas educativas; a repercussão das práticas educativas junto às equipes; o manejo de casos clínicos; os relatórios de cursos ministrados; as informações provenientes de prontuários; a percepção dos participantes; o estabelecimento de monitoramento dos eventos adversos e da qualidade da atenção/gestão. A avaliação processual constitui-se em uma importante estratégia para a qualificação das ações educativas decorrentes da EPS (Feliciano et al., 2008).

As avaliações dos processos educativos necessitam ser sistematizadas para que possam alcançar seus objetivos. Estas têm como objetivo fazer um feedback da efetividade das ações educativas, como estratégia de aperfeiçoamento do processo. As experiências adquiridas nos processos educativos e os respectivos processos necessitam ser continuamente avaliados, com a difusão dos conhecimentos adquiridos e construídos, os quais podem servir de orientação para outros projetos e experiências (Brasil, 2009).

Dentre as atividades educativas, a ação menos desenvolvida é a avaliação, e em virtude da ausência desse recurso, os resultados advindos da implementação das propostas educativas podem ficar submersos. A avaliação dos resultados permite conhecer com mais propriedade as mudanças do processo como um todo, sejam no âmbito da política, sejam no da melhoria de desempenho técnico, no do desenvolvimento de novas competências e, também, no do aperfeiçoamento nas capacidades de gestão e da cultura organizacional (Feliciano et al., 2008). 
Davini, Nervi e Roschke (2002) relatam algumas experiências com a avaliação da educação do trabalho em saúde. Estes autores propõem que o processo de avaliação seja desenvolvido por meio de relatórios, monitoramento e avaliação com pontuações para análise de parâmetros de desempenho. Os aspectos a serem avaliados fazem parte do desenvolvimento do processo educativo, do processo de gestão e do impacto da ação educativa com relação aos objetivos da proposta educativa. Nessa forma de avaliação, utilizam-se os instrumentos de monitorização, autoavaliação e avaliação mista, avaliação por amostragem e também por consultores externos. A experiência mostrou que o uso dessas formas de avaliação permitiu identificar as áreas críticas de educação e as mudanças nas formas de produção (Davini; Nervi; Roschke, 2002).

Metodologicamente, a avaliação do processo educativo pode ser realizada de várias formas. Os objetivos precípuos estão em utilizar-se deste instrumento para definir as estratégias, assim como rever o planejamento e reconfigurar as propostas educativas. E, mais, prever formas de investimento no desenvolvimento de pessoas, assim como avaliar a qualidade dos serviços que são ofertados aos usuários.

\section{Considerações finais}

Conjectura-se que a EPS se tornará efetiva no momento em que transcender a linearidade, as ações pontuais e finalizadoras, preconcebidas para acontecer em determinado local, com conteúdos e estratégias previamente definidos. Ou seja, não se está negando ou excluindo essas ações educativas, até porque elas são importantes em determinadas situações. Mas precisa-se ir além, de se projetarem os programas educativos que estejam de acordo com as necessidades dos educandos, comprometidos com a inovação e a transformação do processo de trabalho, da interatividade e da inserção na gestão-atenção, da integralização da concepção teórica com os fazeres das práticas, pois as ações educativas concernentes à educação permanente não se reduzem tão somente à capacitação técnica e à atualização de conhecimentos. Nesta, importa que as ações educativas sejam vinculadas ao processo de trabalho.

Para ter sentido, as ações educativas precisam transpassar o processo de trabalho, e para se saber sua efetividade, sua avaliação necessita transpassar esse processo. Um dos princípios da EPS é a interação de educadores e educandos, e para que haja adesão e participação dos sujeitos no processo, carece-se de que as propostas educativas aconteçam nos respectivos espaços de trabalho.

A avaliação tem como função primordial a contínua busca de aperfeiçoamento do processo educativo, de modo a construir e apoiar novas propostas, 
reorientar programas e, sobretudo, considerar as mudanças evidenciadas no processo de trabalho. Nessa perspectiva, as informações advindas dos programas educativos são importantes para a gestão de pessoas, em especial para o contínuo desenvolvimento e aperfeiçoamento da atenção em saúde.

O estudo mostra que as avaliações das ações educativas em saúde são ainda incipientes ou inexistentes. A questão é mais abrangente, pois antes de focalizar a avaliação, é preciso ratificar que a educação não pode ser vista como um apêndice, mas, principalmente, fazer parte das políticas institucionalizadas, seja no serviço público, seja nas atividades privadas. Para tanto, deve-se definir quais são os objetivos institucionais e as políticas de gestão de pessoas, além de infraestrutura, investimentos econômicos e financeiros em prol da constituição de uma política institucional de educação no trabalho. Com relação aos programas, é preciso rever e, se for o caso, redimensionar todo o desenho do projeto educativo: as concepções educativas, as necessidades, os objetivos, os recursos e as estratégias.

Portanto, há de se entender que a questão em si não se refere tão somente à avaliação, mas também às formas como estão organizados os programas de educação no trabalho. Porém, salienta-se que a não avaliação implica não se ter a retroalimentação dos resultados e, consecutivamente, não se ter noção do que deve ser revisto, mantido, incorporado ou redimensionado. Nesse sentido, só a avaliação permite manter, rever, atualizar ou redimensionar as propostas educativas.

A pesquisa mostra o parco conhecimento dos sujeitos do estudo sobre a EPS e, de maneira mais acentuada, sobre a avaliação da educação, embora alguns entrevistados tenham respondido que uma das formas de avaliação referia-se a mudanças no comportamento, no fazer, nas condutas e nos comportamentos e, principalmente, como os trabalhadores redimensionavam o processo de trabalho.

Intencionalmente, procurou-se desenvolver a pesquisa em diferentes instituições, cenários e localidades. Na elaboração do projeto, partiu-se do pressuposto de que a educação seria uma estratégia geradora de mudanças no processo de trabalho, fato evidenciado parcialmente por alguns sujeitos da pesquisa. Presume-se que o objetivo do estudo tenha sido em parte respondido.

A PNEPS, como proposta, representa um marco para a efetivação de mudanças no âmbito da formação e do aperfeiçoamento dos trabalhadores da saúde. Entretanto, respeitando-se a estreiteza dos extratos desta pesquisa, buscou-se evidenciar que as concepções educativas propostas pela EPS nos serviços de atenção básica ainda são parcas, enquanto nos hospitais é praticamente inexistente.

Por fim, respeitando-se as limitações, o estudo permite entender que as ações concernentes à EPS somente serão efetivadas quando estiverem vin- 
culadas ao processo de trabalho, no qual se projeta fazer gestão, atenção e educação de forma congregada - no entanto, sem sobreposição de uma atividade à outra. Isso porque a avaliação, supostamente, não se constitui em um ato final ou burocrático, mas sim em uma das mais importantes estratégias de geração de mudanças na educação e, por conseguinte, no processo de trabalho. A avaliação das ações educativas no trabalho constitui-se em uma das mais importantes formas de religação dos saberes teóricos e práticos com as necessidades sociais e institucionais e, sobretudo, dos sujeitos envolvidos no processo, sejam esses trabalhadores, sejam usuários.

\section{Colaboradores}

Luiz Anildo Anacleto da Silva realizou o projeto de pesquisa, analisou os dados e redigiu a primeira versão do artigo. Sandra Marcia Soares Schmidt e Helena Carolina Noal colaboraram na coleta de dados e redação. Eduarda Signor e Iris Elizabete Messa Gomes foram bolsistas de iniciação cientifica voluntárias e participaram da coleta de dados e de todas as etapas de construção do artigo.

Resumen El objetivo del estudio fue conocer los cambios ocurridos en el proceso de trabajo derivados de la educación permanente en salud. Se trató de una investigación cualitativa, descriptiva y exploratoria. Los participantes eran enfermeros actuando en servicios de salud correspondientes a cinco unidades básicas de salud y cinco hospitales de diez ciudades de Rio Grande do Sul, Brasil, entre 2011 e 2012. Los resultados indicaron que el conocimiento de los sujetos de la investigación con relación a la educación permanente era limitado y, de manera general, se desconocían las formas de evaluación de las acciones educativas. Se concluye que la educación en el trabajo, en el segmento investigado, era desarrollada en forma compartimentada, puntual y asistemática, y que la evaluación de las acciones educativas no contribuía para el perfeccionamiento del proceso educativo. Palabras clave enfermería; educación permanente en salud; evaluación; proceso de trabajo. 


\section{Notas}

1 Universidade Federal de Santa Maria, Departamento de Ciências da Saúde, Palmeira das Missões, Rio Grande do Sul, Brasil.

<luiz.anildo@yahoo.com.br>

Correspondência: Universidade Federal de Santa Maria, Curso de Enfermagem, Avenida Independência, 3.751, Vista Alegre, CEP 98300-000, Palmeira das Missões, Rio Grande do Sul, Brasil.

2 Hospital Universitário de Santa Maria, Santa Maria, Rio Grande do Sul, Brasil.

<sandramarciasoares@gmail.com>

3 Hospital Universitário de Santa Maria, Santa Maria, Rio Grande do Sul, Brasil.

$<$ helenacnoal@gmail.com>

4 Universidade Federal de Santa Maria, Palmeira das Missões, Rio Grande do Sul, Brasil. <eduardasignor@hotmail.com>

5 Centro Universitário Franciscano, Programa de Residência em Enfermagem Obstétrica, Santa Maria, Rio Grande do Sul, Brasil.

<irismessagomes@gmail.com>

\section{Referências}

BARDIN, Laurence. Análise de conteúdo. São Paulo: Edições 70, 2011.

BASTABLE, Suzan B. O enfermeiro como educador: princípios de ensino-aprendizagem para a prática de enfermagem. 3. ed. Porto Alegre: Artmed, 2010.

BRASIL. Ministério da Saúde. Secretaria de Gestão do Trabalho e da Educação na Saúde. Departamento de Gestão da Educação em Saúde. Portaria GM/MS n. 1.996/2007. Brasília: Ministério da Saúde, 2007. Disponível em: <http://bvsms.saude.gov.br/bvs/saudelegis/ gm/2007/prt1996_20_08_2007.html >. Acesso em: 15 jun. 2016.

BRASIL. Ministério da Saúde. Secretaria de Gestão do Trabalho e da Educação na Saúde. Departamento de Gestão da Educação em Saúde. Politica Nacional de Educação Permanente em Saúde. Brasília: Ministério da Saúde, 2009. Disponível em: <http://bvsms.saude.gov.br/ bvs/publicacoes/politica_nacional_educacao_ permanente_saude.pdf $>$. Acesso em: 15 jun. 2016.

DAVINI, Maria C.; NERVI, Laura; ROSCHKE, Maria A. Capacitación del personal de los servicios de salud: Organización Panamericana de la Salud. Quito: Organización Mundial de la Salud. Programa de Desarrollo de Recursos Humanos. División de Desarrollo de Sistemas y Servicios de Salud, 2002.

FELICIANO, Kátia V. O. et al. Avaliação continuada da educação permanente na atenção à criança na Estratégia Saúde da Família. Revista Brasileira de Saúde Materno Infantil, Recife, v. 8, n. 1, p. 45-53, 2008.

GIL, Antônio C. Como elaborar projetos de pesquisa. 5. ed. São Paulo: Atlas, 2010. 
LIMA, Sandro G. et al. Educação permanente em SBV e SAVC: impacto no conhecimento dos profissionais de enfermagem. Arquivos Brasileiros de Cardiologia, São Paulo, v. 93, n. 6, p. 630-636, 2009.

MONTANHA, Dionize; PEDUZZI, Marina. Educação permanente em enfermagem: levantamento de necessidades e resultados esperados segundo a concepção dos trabalhadores. Revista da Escola de Enfermagem da USP, São Paulo, v. 44, n. 3, p. 597-604, 2010.

SILVA, Gizelda M.; SEIFFERT, Maria O. L. B. Educação continuada na enfermagem: uma proposta metodológica. Revista Brasileira de Enfermagem, Brasília, v. 62, n. 3, p. 362-366, 2009.
SILVA, Luiz A. A. O processo de trabalho como forma de avaliação da educação permanente em saúde. In: CONGRESSO INTERNACIONAL DE AVALIAÇÃO EM EDUCAÇÃO, 2., Braga, Portugal, 2010. Anais... p. 42-43. Impresso.

SMEKE, Elizabeth L. M.; OLIVEIRA, Nayara L. S. Avaliação participante de práticas educativas em serviços de saúde. Cadernos CEDES, Campinas, v. 29, n. 79, p. 347-360, dez. 2009.

TURATO, Egberto R. Tratado da metodologia da pesquisa clínico-qualitativa. Petrópolis: Vozes, 2003.

Recebido em 11/08/2014

Aprovado em 19/10/2015 